\title{
NYKLASSICISMEN - VART TOG DEN VÄGEN?*
}

\author{
Av MADELEINE LÖFMARCK
}

I kriminalpolitiken, som på många andra områden, tycks utvecklingen beskriva en pendelrörelse: från en ståndpunkt långt ut $\mathrm{i}$ en viss riktning svänger uppfattningarna över till motsatsen, för att sedan obevekligt pendla tillbaka. Förhoppningsvis sker dock samtidigt en viss rörelse framåt. De mest kritiserade utslagen av en ytterlighetsståndpunkt återkommer inte då pendeln svängt tillbaka - åtminstone inte utan en ny förklädnad. Det finns därför anledning att hoppas på framsteg även med det pendlande rörelsemönster som så påtagligt präglar just kriminalpolitiken.

För övrigt är på det kriminalpolitiska fältet avståndet mellan teori och praktik synnerligen märkbart. Den faktiska utvecklingen på straffrättens område speglar bara $\mathrm{i}$ begränsad utsträckning de förfäktade teorierna. De mest utrerade ståndpunkterna omsätts sällan i konkreta reformer. I betydande mån tjänar kriminalpolitiken som testplats för idérika men föga verklighetsförankrade visionärer. Under tiden bestämmer samhällsutvecklingen hur straffrättsskipning och straffverkställighet skall utformas.

Den här, lätt skeptiska synen på kriminalpolitikens funktion förefaller mig vara väl lämpad som utgångspunkt för en undersökning av neoklassicismens betydelse och inverkan på nordisk straffrätt. Neoklassicismen har ju uppfattats som en relativt klart urskiljbar och sammanhängande kriminalpolitisk teori, som får sin speciella innebörd därigenom att den utgör en reaktion mot en annan teori, nämligen behandlingstanken. Vidare har beteckningen neo- eller nyklassicism valts för att visa att det är fråga om ett återuppväckande, om än i delvis ny klädnad, av de tankegångar som präglade den klassiska straffrättsskolan. Men det finns anledning fråga sig, om den markanta omsvängning som alltså framträder i teorin har en motsvarighet i den kriminalpolitiska verkligheten. Har vi fått en nyklassisk straffrätt i Norden? Och hade vi tidigare en på behandlingsideologisk grund utformad straffrätt?

Låt oss först se närmare på behandlingstanken. Det utmärkande för denna

* Artikeln skrevs till ett tysk-skandinaviskt kollokvium vid Max-Planck-Institut für ausländisches und internationales Strafrecht i Freiburg i.B. i maj 1985. 
brukar anges vara att brottslingen sätts i centrum, inte brottet, och att straffen individualiseras för att anpassas till brottslingens person. Individualpreventiva hänsyn tillmäts avgörande vikt. Straffets ändamål är att resocialisera. Straffsystemets berättigande ligger i dess möjlighet att främja individens anpassning. Behandlingstanken framträder som uttryck för rationalitet och humanitet i straffsystemet.

Det har sagts att behandlingstanken kom till starkast uttryck i Sverige; det var där den utvecklades till en ideologi. Visst finns det fog för den uppfattningen. Män som Torsten Eriksson och Torsten Sellin förde ut den svenska synen på straffverkställighet som en vårdande verksamhet och den svenska strafflagstiftningen blev världsunik genom strävan att utmönstra ord och uttryck som gav associationer till skuld och ansvar och ersätta dem med en medicinsk och social terminologi. Kulmen nåddes med Karl Schlyters sista stora lagstiftningsprodukt, förslaget till skyddslag. Med dess påföljdssystem, inarbetat i den år 1965 ikraftträdda brottsbalken, hade Sverige onekligen nått långt på behandlingsideologins väg. Vi hade två tidsobestämda påföljder, ungdomsfängelse och internering, som möjliggjorde för de verkställande organen att låta behandlingsbehovet avgöra när påföljden skulle upphöra. Utrymme gavs för en frivård med ändamålsenlig social inriktning genom regler om villkorlig frigivning och genom skyddstillsyn som ett alternativ till fängelse.

Men verkligheten var aldrig riktigt den som förkunnades i lagstiftningen och av kriminalpolitikerna. Domstolarna utmätte i stor utsträckning straff schablonmässigt - enligt »taxor«. Det gällde i hög grad lydnadsbrott och rattfylleri; de brotten gav regelmässigt en månads fängelse. För allvarligare stöld- och bedrägeribrott, liksom för misshandelsbrott, var ett avsevärt fängelsestraff närmast ofrånkomligt. Detsamma blev så småningom fallet beträffande allvarligare skattebrott. Hela den omfattande bötesbrottsligheten renderade straff enbart med hänsyn till gärningen; gärningsmannens individuella förhållanden intresserade inte domstolen alls så när som på hans ekonomiska situation, som avgjorde storleken på dagsboten.

Man kan konstatera, att de svenska domstolarna endast delvis anpassade sig till de tankegångar som kallas behandlingsideologin. Brottsbalkens uppmaning till iakttagande av vad som krävs för allmän laglydnad gav ett fullgott lagstöd härför. Så småningom utvecklades t o m bland övervaknings- och utskrivningsnämnderna en praxis som klart stred mot grundtankarna $\mathrm{i}$ behandlingsideologin. Det gick helt enkelt inte att bli kvitt rättvise- och proportionalitetstänkandet hos dem som hade hand om lagföring och verkställighet i brottsmål.

När kritiken mot behandlingstanken i början av 1970-talet växer fram i de nordiska länderna är det således endast delvis den genomförda och praktiserade straffrätten man reagerar mot. I hög grad är det fråga om en lärostrid. Till en 
del förklaras denna av att ett generationsskifte sker bland de tongivande kriminalpolitiska debattörerna. De nya idéerna kom tidigast till uttryck i Finland. I Finland hade behandlingstankegångarna haft allra svårast att vinna genomslag i lagstiftning och straffverkställighet. En företrädare för det finska kriminalvårdsväsendet uttryckte vid det nordiska kriminalistmötet i Helsingfors i juni 1984 saken ungefär så här:

"Våra fångar satt fortfarande $\mathrm{i}$ gamla, överfyllda anstalter långt borta från tätorterna, och psykologiskt utbildad personal kom bara dit någon enstaka gång. Någon behandling var det aldrig fråga om. Så när kriminalpolitikerna stod upp och förkunnade att behandlingsidéerna var förfelade och därmed framstod som radikala hänförde de sig på förhållandena i de finska fängelserna sådana de förblivit under ytan av en aldrig realiserad kriminalpolitisk behandlingsideologi«.

Samma förhållande fastslår P. O. Träskman i en artikel om svensk och finsk strafflagsutveckling i anledning av det nyligen avhållna 250-årsjubiléet av 1734 års lag: ${ }^{\text {): }}$

»För Finlands del innebär (nyklassicismen) att det åter finns överensstämmelse mellan den nationella kriminalpolitiken och de allmänna nordiska strömningarna. Då landet aldrig helt hunnit med $\mathrm{i}$ den utveckling mot individualprevention som skedde $\mathrm{i}$ andra nordiska länder betydde allmänpreventionens nya frammarsch $\mathrm{i}$ dessa att Finland $\mathrm{t} o \mathrm{~m}$ kunde förefalla som ett föregångsland«.

Vad var det då man framför allt kritiserade hos behandlingsideologin? Kritiken var motsägelsefull. Den gick dels ut på att behandlingstanken ledde till en eftergivenhet gentemot brottslingarna - fängelsestraff undveks med hänvisning till bristande social anpassning. Men man hävdade också att den medförde en alltför sträng behandling av de sämst ställda lagöverträdarna. Mot dessa blev reaktionen långvarig med hänvisning till ett behandlingsbehov; straffsystemet var socialt orättvist. Kritiken kan sammanfattas i fyra punkter:

1) Huvudorsaken till kriminalitet läggs hos individen och medför den orealistiska föreställningen att man kan komma till rätta med brottsligheten genom individorienterade - terapeutiska - åtgärder.

2) Brottsligheten behandlas som en sjukdom, vilket döljer att kriminalitet är en följd av att samhället bestämmer att vissa förfaranden är brottsliga. Man undviker härigenom frågan vad som är den verkliga grunden för straffsystemet.

3) Man frånkänner kriminaliteten karaktär av medvetet handlande; ansvar är ovidkommande.

1) 1734 års lag 250 år. Svensk Juristtidning, Sthlm 1984 s. 830. 
4) Kriminalvårdsanstalterna betraktas som sjukhusmiljöer, vilket förtränger fängelseverkligheten och döljer de reella konflikter som tvånget innebär.

Enskilda forskare och andra deltagare i den nordiska kriminalpolitiska debatten gav uttryck för kritik enligt de här linjerna under 1970-talets första år. I mitten av detta årtionde kom kritiken till mera officiellt och samlat uttryck i de olika länderna. I Finland publicerade straffrättskommittén sitt förslag till ny finsk strafflag (principbetänkande och $\mathrm{s} k$ stomplan) år 1976. I Danmark sammanfattades följande år den nya synen i betänkandet Alternativer til frihedsstraf - et debatoplæg, i Sverige samma år i rapporten Nytt straffsystem, som hade utarbetats av en arbetsgrupp inom Brottsförebyggande rådet. I Norge skedde det i den år 1978 avgivna »kriminalmeldingen«.

Grundtanken i kritiken uttrycktes i ett sammanfattningsblad till den svenska rapporten så här:

»Enligt arbetsgruppen bör anspråken på rättvisa, proportionalitet och humanitet ha stort utrymme. Lagbrytaren bör inte behandlas som vårdfall när han inte är sjuk. Strafflagen måste bygga på den enskildes ansvar för sina handlingar. Lagen bör tala klarspråk. Straffet är och måste vara ett obehag. Det skall stå i proportion till brottets svårhet. Det skall kunna förutses och utmätas konsekvent efter brottet och inte efter lagbrytarens sociala situation«.

En hörnsten i nyklassicismen är således kravet på proportionalitet mellan brott och straff. Till en del innebär detta, som man i den allmänna debatten har betonat, att allmänpreventiva tankegångar får ökad tyngd. Medan behandlingstanken satte individualpreventionen i centrum medför nyklassicismens förskjutning av tyngdpunkten från brottslingen till brottet att straffhotets och straffets betydelse när det gäller att styra handlandet hos människor i allmänhet blir viktig. Men det väsentliga är att man vill återinföra en relation mellan brott och straff, som behandlingstanken - som teori - hade tappat bort. Därmed måste straffvärdesfrågorna bli centrala; proportionalitet förutsätter att olika gärningars straffvärde kan fastställas. Detta är, som jag återkommer till i det följande, kanske den mest kritiska punkten i den nyklassiska teorin. Humanitetskravet, som vidare betonas i sammanfattningen, har hos nyklassikerna innebörden att endast ett proportionellt straff är humant, medan ett straff bestämt med hänsyn till lagöverträdarens behov av social rehabilitering blir orättvist och därmed inhumant. Här finns en konflikt: behandlingsteorin grundade sin anpassning av straffsystemet till individen på just humanitetsskäl. Nyklassikerna ser istället som humant att tillerkänna människor ansvar för sina handlingar. Och man reagerar mot bruket av eufemismer som behandling, skydd och vård när det är fråga om påförande av lidande om obehag.

Ett decennium har passerat sedan vi i de nordiska länderna således officiellt 
bröt med behandlingstanken. Hur ser då verkligheten ut? I vad mån och på vilket sätt har de nyklassiska idéerna förmått förändra strafflagstiftning och kriminalvård? Mina iakttagelser då jag nu skall försöka ge en bild av dagens nordiska förhållanden är av naturliga skäl främst hämtade från Sverige. Men jag tror att den bilden är ganska representativ, och jag hoppas att den kan kompletteras av mina kollegor från de andra länderna i den följande diskussionen.

Lagstiftningstakten på straffrättens område har, liksom på andra rättsområden, varit mycket hög i Sverige under de senaste tio åren. Det är därför inte så lätt att få en verklig överblick över reformverksamheten och därmed en möjlighet att klarlägga nyklassicismens genomslagskraft. Redan genom att se på några olika lagstiftningsärenden torde man dock få en ganska god bild av vad som verkligen skett och sker och hur de olika punkterna i den deklarerade inställningen har klarat konfrontationen med verkligheten i form av lagstiftarens vilja och myndigheternas agerande.

Som klara utslag av nyklassiska strävanden kan man beteckna avskaffandet $a v$ de två tidsobestämda påföljderna ungdomsfängelse och internering år 1979 respektive 1981. Den senare reformen försenades avsevärt, vilket hade ett uppenbart samband med att några starkt kriminellt belastade personer utförde vissa grova brott och för en tid stod $i$ centrum för massmedias intresse; verkligheten blev återigen ett hinder i genomförandet av idéerna. I Norge avskaffades ungdomsfängelse så tidigt som år 1975, medan »sikring« ännu finns kvar men används i mycket liten omfattning (praktiskt taget enbart för såsom farliga ansedda våldsbrottslingar). Den s k straffelovkommisjonen föreslår i sitt år 1983 framlagda första delbetänkande att sikring avskaffas men vill införa en särskild form av fängelsestraff för tillräkneliga personer som begått allvarliga brott och kan antas vara farliga. En längsta tid skall fastställas men kunna förlängas om behov föreligger.

Proportionalitetskravet innebär ju att frågan om olika gärningars straffvärde blir centralt. I Sverige har sådana frågor framför allt förts fram i diskussionen om den $\mathrm{s} \mathrm{k}$ traditionella brottsligheten kontra den ekonomiska (och $\mathrm{i}$ någon mån den organiserade) brottsligheten. En markant förskjutning har skett av tyngdpunkten i lagstiftningen från den traditionella till den ekonomiska brottsligheten. På sistnämnda område har, som väl numera är bekant i vår omvärld, en intensiv lagstiftningsverksamhet pågått sedan 1970-talets slut. Redan i början av 1970-talet markerades denna omsvängning genom att brottet skattebedrägeri i straffhänseende likställdes med stöld, bedrägeri, förskingring och andra traditionella förmögenhetsbrott. Den $\mathrm{s} k$ förmögenhetsbrottsutredningen föreslog härom året en generell nedvärdering av de sistnämnda brotten $\mathrm{i}$ förhållande till bl a skattebrott. Remissutfallet blev i det här avseendet övervägande negativt. $\mathrm{Bl}$ a framhölls det att förslaget inte grundades på någon 
undersökning av vad som är den allmänna uppfattningen om de traditionella förmögenhetsbrottens relativa straffvärde.

Den nu nämnda kritiken gäller en central svårighet i den nyklassiska läran. Hur skall man kunna genomföra den för proportionaliteten nödvändiga bestämningen av olika brotts straffvärde? Hur detta skall gå till berörs inte i de ovan nämnda principbetänkandena, liksom inte heller i andra framställningar av de nyklassiska tankegångarna. Att kritikerna har skjutit in sig på den här punkten är naturligt. Man konstaterar att det i betänkandena genomgående hävdas att det skall råda överensstämmelse mellan lagens straffsatser och det allmänna rättsmedvetandet, men att man där tiger om hur detta allmänna rättsmedvetande skall fastställas. En viss forskningsfientlig inställning har ansetts kunna inläsas i åtminstone den svenska rapporten. Intervjuundersökningar är tydligen inte något som tilltalar lärans förespråkare. För svensk rätts del har frågan bollats över till den s k fängelsestraffkommittén, som i sitt till hösten 1985 aviserade slutbetänkande lär komma att ingående behandla frågor om olika brotts straffvärde. I Norge har straffelovkommisjonen haft i uppdrag bl a att göra straffvärdejämförelser mellan olika brottstyper. I sitt delbetänkande har den ägnat ett kapitel åt detta svåra ämne. Där jämförs bl a förmögenhetsbrott och våldsbrott och man finner en viss brist i proportionaliteten. För att åtgärda denna föreslås dels en skärpning beträffande vissa våldsbrott, dels en möjlighet att döma till böter för vissa förmögenhetsbrott som idag endast har fängelse i straffskalan. Skattebrotten anses för lågt värderade och föreslås $\mathrm{i}$ grova fall kunna ge fängelse 6 år, som fallet är i svensk rätt. Även miljöbrott anses för lågt värderade.

Ett uppmärksammat lagstiftningsärende i Sverige under hösten 1984 illustrerar väl det som nu berörts. Den s k narkotikakommissionen, som tillsattes av den år 1982 tillträdande socialdemokratiska regeringen, hade i en PM konstaterat, att konsumtion av narkotika och innehav av narkotika i omedelbart samband med egen konsumtion inte täcks av straffansvaret enligt den svenska narkotikastrafflagen; detta till skillnad mot vad som gäller i t ex Norge och Finland. Efter en diskussion om den principiella inställningen till straff för angrepp riktade mot egen rättssfär och tänkbara effekter på missbrukarvården av en kriminalisering av själva konsumtionen förordade kommissionen, att sådan kriminalisering inte skulle införas. En stark opinion för kriminalisering växte fram, stödd av bl a flera organisationer på narkotikabekämpningens område. Regeringen framlade en proposition vari den biträdde kommissionens ståndpunkt. Inför riksdagsbehandlingen genomfördes och publicerades en gallupundersökning (SIFO), som utvisade att $95 \%$ av svenska folket ansåg att konsumtion av narkotika skulle vara straffbelagt. Propositionen antogs av den socialdemokratiska och kommunistiska riksdagsmajoriteten. 
Detta lagstiftningsärende är intressant som ett »test« på de allmänpreventiva tankegångarnas betydelse $\mathrm{i}$ det praktiska lagstiftningsarbetet. Huvudargumentet hos dem som förordade kriminalisering var, att ett straffhot skulle verka avhållande på - framför allt unga - människor som ännu inte fastnat i missbruk. En sådan argumentering är helt i linje med de nyklassiska idéerna. Enligt den svenska uttolkningen av dessa, den nämnda BR A-rapporten, kan det ingalunda krävas av den som anför allmänpreventiva skäl för en kriminalisering, att han förmår bevisa att ett straffhot verkligen skulle avhålla människor från att begå brott. ${ }^{2)}$ I samma rapport fastslås för övrigt, att kriminalisering endast kan motiveras av allmänpreventiva skäl, medan individualpreventiva bedömningar kommer in först vid utmätande av straff för konkreta gärningar. ${ }^{3)}$ Debatten om kriminalisering av narkotikakonsumtion visade på ett slående sätt hur dessa principdeklarationer kom till korta i praktiken. De allmänpreventiva synpunkterna tillbakavisades med argument som klingade ytterst välbekant från behandlingsideologins glansdagar; allmänprevention är fult och inhumant, den som begår oönskade handlingar och därigenom röjer sociala problem skall vårdas, inte straffas. Denna begravning av nyklassicismen skedde - och det är väl i det här sammanhanget inte utan intresse - i stort sett under tystnad. I spaden höll flera av dem som stått på barrikaderna i kampen mot behandlingstanken. Pendeln hade svängt tillbaka - åtminstone i fråga om missbrukarkriminalitet.

Verkligheten torde vara den, att proportionalitetstänkandet inte haft förutsättningar att vinna gehör över hela det kriminalpolitiska fältet. När det rör sig om lagöverträdare med sociala problem har behandlingsideologin fortfarande ett starkt fotfäste i svensk kriminalpolitik. Låt mig ge ännu ett exempel som belyser detta. Hösten 1984 lade regeringen fram en proposition om ändringar i rattfyllerilagstiftningen. I den föreslogs bl a att inte enbart fängelse utan även böter skulle ingå i straffskalan för »normalt« rattfylleri. Förslaget motiverades bl a med att allmänpreventionen hade »verkat« och inte längre krävde frihetsberövande för rattfylleri, att flertalet rattfyllerister var alkoholister på vilka fängelsestraff saknade verkan, att detta brott hade ett relativt för högt straffvärde och att det rådde olikhet $\mathrm{i}$ rättstillämpningen över landet; vissa tingsrätter hade i stort sett övergett principen om fängelse vid rattfylleri medan andra höll fast vid den. Det visade sig att propositionen skulle komma att falla i riksdagen och den återkallades. Debatten kring förslaget har varit synnerligen livlig. Bl a har man menat, att det var nykterhetsivrarnas lobbyverksamhet och inte den allmänna rättsuppfattningen som avgjorde propositionens öde.

2) Rapport 1977:7 s. 199 .

3) A.a. s. 196. 
Att fastställa vilken kriminalpolitisk grundinställning denna proposition ger uttryck för är inte lätt. Två faktorer, vilkas betydelse i sammanhanget knappast kan förnekas, behandlades inte som bevekelsegrunder i själva propositionen, och det är därför svårt att veta vilken relativ betydelse de hade. Den ena är Högsta domstolens praxis. I en rad avgöranden har HD successivt öppnat för en ny påföljdsbestämning i rattfyllerimål. Individuella faktorer, främst dokumenterat missbruk och påbörjad behandling, har beaktats och föranlett icke frihetsberövande påföljd i flera fall. Var regeringen inte nöjd med att praxis således beskrev en utveckling bort från obligatoriskt fängelsestraff för rattfylleribrott? I så fall gav den uttryck för nyklassiska tankegångar, enligt vilka lika brott bör ge lika straff. Den andra faktorn är kravet på besparingar inom kriminalvården. På detta, liksom på alla andra områden av svenskt samhällsliv, har regeringen uppställt hårda besparingskrav som led i försöken att komma tillrätta med de samhällsekonomiska svårigheterna. Svensk kriminalvård är dyrbar, både absolut och i jämförelse med andra länder. Vid 1980-talets början var de svenska anstalterna överbelagda och köerna växte. Att bygga nytt ställde sig orimligt dyrt. Var förslaget att radikalt skära ner den dominerande grupp fängelsedömda som rattfylleristerna utgör ett besparingsförslag? I varje fall är det klart, att ekonomiska överväganden har en stark realitet i dagens svenska kriminalpolitik och att de bidrar till svårigheterna att fastställa i vad mån nyklassiska idéer har förmått tränga igenom på bekostnad av behandlingstänkandet.

Nämnas kan i det här sammanhanget, att den norska straffelovkommisjonen anser »promillekjøring« alltför strängt värderad jämfört med andra allvarliga trafiköverträdelser och förslår en nyansering av straffet. I Finland har en sådan sänkning ägt rum utan - efter vad som rapporteras - beaktansvärda negativa effekter.

Den svenska propositionen om rattfylleristraffet visar enligt min mening, att proportionalitetstanken i nyklassicismen endast delvis blivit lagstiftarens ledstjärna. Att söka råda bot på en bristande likhet i straffmätning och påföljdsval över landet är visserligen i linje med den-principen. Detsamma skulle kunna sägas om strävan att ge rattfylleribrottet ett lägre straffvärde därför att det för närvarande skulle vara »övervärderat«. Men när det gällde att fastställa vilket straffvärde detta brott skulle anses ha grundade man sig inte på några medvetna försök att klarlägga allmänhetens uppfattning. Snarare undvek man detta, och när förslaget stötte på patrull var man inte beredd att acceptera att man missbedömt det allmänna rättsmedvetandet.

Hur har det gått med föresatserna att rensa bort straffrättens eufemismer? BRÅ-rapportens tal om straff har knappast rått på terminologin i lag och debatt. Vi talar hellre om påföljder och sanktioner än om straff, vi har inte 
fångar utan intagna på våra kriminalvårdsanstalter. Den nyhet som kan förväntas i det svenska påföljdssystemet kallas kontraktsvård; mera om det i det följande.

När det gäller den för nyklassicismen grundläggande tanken att den enskildes ansvar för sina handlingar skall erkännas av straffsystemet är bilden splittrad. I den praktiskt viktiga frågan hur man skall finna alternativ till fängelsestraff med bibehållen eller förstärkt betoning av ansvar för och reaktion på ett handlande har man $\mathrm{i}$ Sverige inte hunnit långt. Samhällstjänst $\mathrm{i}$ olika former, där kopplingen mellan gärning och påföljd markeras, har hittills inte vunnit gehör. Något som kanske är typiskt för vårt land är väl den reaktion mot denna tanke som har kommit från fackligt håll: arbete skall inte vara ett straff, och uppgifter som fackets medlemmar utför som normalt arbete skall inte utföras av lagöverträdare som ett straff. I Danmark och Norge pågår däremot försöksverksamhet med samhällstjänst, som kan komma att leda till införandet av en sådan brottspåföljd. Den svenska utredning, som nyligen avslutat en genomgång av tänkbara alternativ till fängelse, den s k frivårdskommittén, har ställt sig positiv endast till ett sådant, nämligen kontraktsvård för alkohol- och narkotikamissbrukare. Detta utredningsresultat, som regeringen har för avsikt att samordna med nya försök att åstadkomma förändring vad gäller påföljd för rattfylleri, kan i och för sig väl förenas med nyklassiska argument: det är kriminaliseringsfrågan och bestämmandet av straffnivå som styrs av allmänpreventiva hänsyn, medan individuella faktorer skall beaktas vid straffmätning och påföljdsval inom de därvid givna ramarna. Men idén med kontraktsvård ligger onekligen närmare de principer som uppbar behandlingsideologin.

Ett aktuellt svenskt lagförslag rör i särskilt hög grad frågan om ansvar och skuld, nämligen den s k socialberedningens förslag till ny reglering av lagföringen av psykiskt störda lagöverträdare. En genomgående tanke i det förslaget är, att psykiskt störda lagöverträdare i större utsträckning skall föras in under kriminalvården. Endast de mest störda skall hållas utanför det vanliga påföljdssystemet. Remisskritiken på förslaget har varit kraftig. Bl a har det betecknats som ett misstag när beredningen påstått, att de straffrättsliga skuld- och ansvarsprinciperna väl skulle tillåta att många av dem som idag inte anses kunna »svara för« sina handlingar döms till fängelse. I förslaget kan emellertid också inläsas tankegångar av nyklassisk natur. Den nuvarande ordningen, att en allvarlig lagöverträdelse kan föranleda endast en kort tids frihetsberövande - när något vårdbehov inte anses kvarstå - medan ett lindrigt brott kan följas av lång tids frihetsberövande - på grund av vårdbehov - kritiseras av beredningen. Dess förslag är bl a avsett att råda bot på dessa, mot proportionalitetsprincipen stridande förhållanden.

Den nyklassiska tanken att lagen bör tala klarspråk när det gäller strafftidens 
längd och att institutet villkorlig frigivning därför är en tvivelaktig ordning har på ett slående sätt undergrävts i svensk strafflagstiftning under de år som gått sedan BR $\AA$-rapporten skrevs. Det har skett genom att ett annat krav också pockat på att bli tillgodosett, nämligen det nämnda besparingskravet. I juli 1983 infördes obligatorisk villkorlig frigivning från fängelsestraff efter halva strafftiden, dock minst två månader. Att det var kostnadsaspekten som var avgörande bekräftas dock inte från regeringshåll. I årets statsverksproposition heter det att reformen skedde i syfte att minska användningen av frihetsstraff och av intresset av att öka förutsebarhet och rättvisa samt avveckla onödig byråkrati. ${ }^{4)}$ Onekligen kan förutsebarheten vad gäller villkorlig frigivning $i$ det enskilda fallet sägas ha ökat i nyklassisk anda. Men viktigare ur den synpunkten är självfallet att en systematisk villkorlig frigivning efter halva tiden gör lagens och domstolens - straffangivelse till allt annat än klarspråk! Den ovan nämnda fängelsestraffkommittén lär i sitt aviserade slutbetänkande komma att föreslå en återgång till den förutvarande ordningen med obligatorisk villkorlig frigivning efter $2 / 3$ av tiden. Den norska straffelovkommisjonen avvisar det svenska systemet och framhåller att, om man vill reducera fängelsestraffens längd, det är bättra att direkt utmäta kortare straff.

En annan betydelsefull, med nyklassicismen svårförenlig företeelse i dagens svenska kriminalpolitik är de åtgärder som syftar till att minska antalet lagföringar genom utökade möjligheter till rapport- och åtalseftergift. Denna s $\mathrm{k}$ avkriminalisering på straffprocessuell väg befordrar knappast förutsebarhet och likabehandling. Även bakom detta reformarbete ligger självfallet resurshänsyn: polis- och åklagarmyndigheter har en alltför stor arbetsbörda för att kunna ägna sig åt den allvarliga brottsligheten i den omfattning som krävs. En viktig reform av detta slag är införandet den 1 april 1985 av en helt ny grund för åtalsunderlåtelse, nämligen att det kan antas att villkorlig dom skulle bli påföljden och det finns särskilda skäl till åtalsunderlåtelse samtidigt som en sådan inte skulle innebära att något väsentligt allmänt eller enskilt intresse blev åsidosatt. ${ }^{5)}$

Resursmotivet bakom ökningen av möjligheterna till åtalsunderlåtelse för oss åter till den kanske mest markanta tendensen i dagens svenska kriminalpolitik, nämligen koncentrationen på den ekonomiska brottsligheten. Många företrädare för nyklassiska idéer i Norden har uppfattat det som en primär uppgift $\mathrm{i}$ ett nytt straffsystem att "vikta om» brotten och därvid tona ner den traditionella brottsligheten i förhållande till främst ekonomisk brottslighet; detta har ju ovan berörts i anslutning till vad som sagts om det allmänna rätts-

4) Prop. $1984 / 85: 100$ bil. 4 s. 29 f.

5) SFS $1985: 13 \mathrm{ff}$. 
medvetandets betydelse. I Sverige har dessa tankar fått en påtagligt partipolitisk karaktär, som på ett olyckligt sätt låst positionerna i lagstiftningsarbetet och knappast befrämjat en realistisk inställning. Som ett utslag härav vill jag beteckna det initiativ till särreglering av de s k EKO-fångarnas behandling, som den svenske justitieministern tagit och som skall resultera $\mathrm{i}$ ett förslag under våren 1985. Utgångspunkten är att dessa personer generellt har en stabil social situation och därmed inte samma behov av frigång, permissioner etc. som andra intagna - en uppfattning som, om man ser till dem som faktiskt dömts för EKO-brott, i hög grad torda sakna verklighetsförankring och som knappast är i linje med det nyklassiska likabehandlingskravet. $\left.{ }^{6}\right)$ Det finns anledning att, som P. O. Träskman gör i sin ovan nämnda artikel, varna för en tendens till uppdelning av det tidigare enhetliga straffsystemet på tre delsystem: ett som tillämpas på småbrott av enskilda personer, ett som gäller för ekonomiska brott förövade inom kollektiv och ett som endast gäller traditionella brott förövade av sådana personer som vi blivit vana vid att se som brottslingar. ${ }^{7)}$ En sådan varning är befogad alldeles oavsett vilken uppfattning man har om den traditionella brottslighetens respektive den ekonomiska brottslighetens relativa straffvärde, och den är definitivt berättigad från en nyklassisk utgångspunkt.

Den ofullständiga bild jag här sökt teckna av nyklassicismens betydelse för svensk och i någon mån annan nordisk straffrätt kan kanske kompletteras med några intryck från ett nyligen avhållet seminarium vid juridiska institutionen $\mathrm{i}$ Stockholm. Seminariets ämne var frågan om straffsystemets grund, framför allt frågan om etiska normers betydelse vid strafflagstiftning och -tillämpning. Det intryck som inledningsanföranden (av etiker wav facket « - från filosofi och teologi -, företrädare för lagstiftningsverksamheten och rättstillämpningen och för rättsvetenskapen) och debatt efterlämnade var avsaknaden av ideologi i dagens svenska straffsystem. Den avfärdade behandlingsideologin har efterträtts av - ingenting. Bakom lagstiftarens flitiga hänvisande till vad som »krävs« ifråga om reaktioner på olika områden finns ingen genomtänkt motivering. Etiska överväganden kan möjligen ligga bakom, men då endast som rationella skäl, t ex att vissa grundnormer måste upprätthållas för att samhället skall fungera. Något »absolut« etiskt normtänkande, som uttalanden i lagförarbeten och i den politiska debatten kan ge intryck av, finns egentligen inte. Ur nyklassicismens synpunkt är detta högst prekärt, ty en rationell etisk argumentering för i en straffvärdesdiskussion till resultat som knappast uppfyller proportionalitetskravet. Det kravet förutsätter grundläggande etiska ställningstaganden, som dagens svenska jurister står främmande inför. Vad man istället ägnar sig åt är att skapa

6) Jfr. det i departementspromemerian DsJu 1985:1 Lyxfångar - finns dom? presenterade utredningsresultatet.

7) Träskman, P. O., SvJT 1984 s. 839. 
likformighet och samordning - genom straffmätningsundersökningar, praxisdiskussioner och liknande verksamhet. Med datateknikens hjälp kan man förvisso nå långt på den vägen och - till synes - mot den nyklassiska målsättningen. Men så länge man inte har någon egentlig uppfattning om varför en samhällsreaktion måste till vid en viss handlingstyp och på vilken nivå reaktionen bör ligga blir dessa lovvärda ansträngningar snarast belägg för att inte heller nyklassicismen höll måttet som kriminalpolitiskt riktmärke.

\section{KÄLLOR}

Alternativer til frihedsstraf - et debatoplæg. Betænkning nr. 806, København 1977.

Narkotikakommissionens PM nr. 8.

Nytt straffsystem. Idéer och förslag. Arbetsgruppen rörande kriminalpolitik. BRß Rapport 1977:7.

Om kriminalpolitikken. Stortingsmelding nr. 104 (1977-78), Oslo 1978.

NOU 1983:57. Betänkande av straffelovkommișjonen.

Prop. 1984/85:21 rörande påföljder för trafikonykterhetsbrott.

Prop. 1984/85:46 om ändringar i narkotikastrafflagen (1968:64), $\mathrm{m} \mathrm{m}$.

Riksdagens skrivelse 1984/85:91.

SOU 1956:55 Skyddslag. Förslag av straflagberedningen.

SOU 1983:50 Översyn av lagstiftningen om förmögenhetsbrott utom gäldenärsbrott.

Betänkande av förmögenhetsbrottsutredningen.

SOU 1984:32 Nya alternativ till fängelsestraff. Slutbetänkande av frivårdskommittén.

SOU 1984:64 Psykiatrin, tvånget och rättssäkerheten. Betänkande av socialberedningen.

Straff och rättfärdighet - ny nordisk debatt. Redigerad av Sten Heckscher m.fl. Stockholm 1980.

Straffrättskommitténs betänkande 1976:72. Helsingfors 1976.

Träskman, P. O., Brottspåföljder och brottmålsförfarandet - rättsutvecklingen i Finland och i Sverige under femtio år. Svensk Juristtidning 1984. 1734 års lag 250 år, s. $826 \mathrm{ff}$.

Adresse: Professor, jur. dr. Madeleine Löfmarck

Juridiska fakulteten

Stockholms Universitet

S-106 91 Stockholm. 